\title{
Tumor-Derived CXCL1 Promotes Lung Cancer Growth via Recruitment of Tumor-Associated Neutrophils
}

\author{
Ming Yuan, ${ }^{1}$ Ha Zhu, ${ }^{1}$ Junfang Xu, ${ }^{2}$ Yuanyuan Zheng, ${ }^{1}$ Xuetao Cao, ${ }^{1,2}$ and Qiuyan Liu ${ }^{1}$ \\ ${ }^{1}$ National Key Laboratory of Medical Immunology \& Institute of Immunology, Second Military Medical University, \\ Shanghai 200433, China \\ ${ }^{2}$ Institute of Immunology, Zhejiang University School of Medicine, Hangzhou 310058, China
}

Correspondence should be addressed to Xuetao Cao; caoxt@immunol.org and Qiuyan Liu; liuqy@immunol.org

Received 24 February 2016; Revised 10 May 2016; Accepted 2 June 2016

Academic Editor: Marco Velasco

Copyright (C) 2016 Ming Yuan et al. This is an open access article distributed under the Creative Commons Attribution License, which permits unrestricted use, distribution, and reproduction in any medium, provided the original work is properly cited.

\begin{abstract}
Neutrophils have a traditional role in inflammatory process and act as the first line of defense against infections. Although their contribution to tumorigenesis and progression is still controversial, accumulating evidence recently has demonstrated that tumorassociated neutrophils (TANs) play a key role in multiple aspects of cancer biology. Here, we detected that chemokine CXCL1 was dramatically elevated in serum from 3LL tumor-bearing mice. In vitro, 3LL cells constitutively expressed and secreted higher level of CXCL1. Furthermore, knocking down CXCL1 expression in 3LL cells significantly hindered tumor growth by inhibiting recruitment of neutrophils from peripheral blood into tumor tissues. Additionally, tumor-infiltrated neutrophils expressed higher levels of MPO and Fas/FasL, which may be involved in TAN-mediated inhibition of $\mathrm{CD} 4^{+}$and $\mathrm{CD} 8^{+} \mathrm{T}$ cells. These results demonstrate that tumorderived CXCL1 contributes to TANs infiltration in lung cancer which promotes tumor growth.
\end{abstract}

\section{Introduction}

Lung cancer is the most commonly diagnosed malignancy with approximately 224,000 new cases in 2014 in western world [1]. Although great advances have been made in the early detection and therapeutic approaches, the morbidity of lung cancer is still raising and leading to the first cause of death in cancer [1]. Chronic inflammation is strongly linked to lung cancer initiation and progression. In lung cancer patients or experimental animal models, the composition and phenotype of neutrophils/granulocytic cells in blood are dramatically altered $[2,3]$. Multiple evidence shows that neutrophils are presented in the tumor sites or paratumor tissue in various types of tumors, and the density of neutrophils is an independent factor for predicting the prognosis of cancer patients [4]. Tumor-derived chemokines and cytokines recruit myeloid cells into tumor microenvironment and educate them into protumor phenotype [5]. However, the mechanisms that are involved in the recruitment of neutrophils to the tumor microenvironment are far from clear. In hepatocellular carcinoma (HCC), tumor-derived chemokine
CXCL5 mediate the recruitment of neutrophils, and the density of TANs is associated with poor prognosis of cancer patients [6]. The chemokine receptor CXCR2 is expressed in neutrophils/granulocytic cells. When CXCR2 interacts with its ligand, neutrophils are recruited to the inflamed site [7]. Additionally, Lewis lung carcinoma cells-derived oxysterol plays a key role in the recruitment of CXCR2 ${ }^{+}$ tumor-promoting neutrophils into tumor tissues [8]. Tumorexpressed chemokines CXCL8 and CXCL6 are also involved in the neutrophils infiltration [9].

Chemokine (C-X-C motif) ligand 1 CXCL1 (also referred to as GRO-1) binds to CXCR2, which is highly expressed on the surface of neutrophils [10]. In both infection and cancer microenvironment, CXCL1 is elevated by various stress-inducing factors, including PGE2 [11]. Elevated levels of CXCL1 and CXCR2 positively correlate with the poorer prognosis of cancer patients [12, 13]. It has been reported that CXCL1/CXCR2 density is strongly associated with the number of neutrophils in the tumor microenvironment and can be an independent factor for predicting the prognosis of patients with hepatocellular carcinomas [14]. In animal 
studies, CXCL1 receptor CXCR2 deficiency prevents from tumorigenesis in colitis-associated cancer [15] and colorectal cancers [16] by inhibiting myeloid-derived suppressive cells (MDSCs) infiltration. Furthermore, CXCL1-mediated myeloid cells infiltration is associated with therapeutic response in breast cancer [17]. Recently, it has been reported that stably silencing of CXCL1 can inhibit tumor growth in HCC [18], and knocking down of CXCL1 expression can inhibit tumor growth in colorectal liver metastasis [19]. Additionally, autocrine and paracrine of CXCL1 can also promote tumor invasion and metastasis [17, 20, 21].

In this study, we found that the level of CXCL1 in serum was significantly upregulated in $3 \mathrm{LL}$ lung cancer bearing mice. Knocking down CXCL1 expression in 3LL cells significantly inhibited neutrophils infiltration, resulting in reducing tumor growth in vivo. Tumor-infiltrated neutrophils in tumor tissues expressed higher levels of MPO and Fas/FasL, which may be involved in TAN-mediated inhibition of $\mathrm{CD}^{+}$ and $\mathrm{CD}^{+} \mathrm{T}$ cells. In conclusion, tumor-derived CXCL1 contributes to neutrophils infiltration in lung cancer which promotes tumor growth.

\section{Materials and Methods}

2.1. Mice and Cell Lines. C57BL/6J mice (6-8 weeks) were obtained from Joint Ventures Sipper BK Experimental Animal Company (Shanghai, China). All experimental manipulations were undertaken in accordance with the National Institutes of Health Guide for the Care and Use of Laboratory Animals, with the approval of the Scientific Investigation Board of the Second Military Medical University, Shanghai, China. A Lewis lung carcinoma sub-line 3LL was maintained as described previously [22]. A mouse epithelial cell line MLE and a human non-small lung carcinoma cell line A549 were purchased from ATCC.

2.2. CXCL1 Knockdown. 3LL cells $\left(2 \times 10^{5} /\right.$ well $)$ were plated into 6-well plates and transfected with negative control (NC) or CXCL1-specific shRNA plasmids (design by Gene Pharma, China) using jetPEI (Polyplus-transfection, France) as described previously [23]. Stably silenced transfected cell clones were selected in $800 \mu \mathrm{g} / \mathrm{mL}$ G418 for 14 days; GFPexpressing cells were selected by FACS sorting system and analyzed by real-time PCR and ELISA for CXCL1 expression and secretion.

2.3. Flow Cytometric Analysis. For analysis of tumorinfiltrating cells, tumor-infiltrating lymphocytes (TILs) were isolated from transplanted tumors and suspended into single cells. For analysis of the compartment of immune cells in the peripheral blood, blood was collected in a tube with heparin and incubated with Tris- $\mathrm{NH}_{4} \mathrm{Cl}$ to remove erythrocytes. Cells were stained with monoclonal anti-mouse antibodies as follows: CD45-BV510, CD3e-PE-Cy7, CD $8 \alpha-\mathrm{PE}, \mathrm{CD} 4-\mathrm{PE}-$ Cy5, CXCR2-PerpCy5.5, CD11b-APC, Ly6G-PE, Ly6C-FITC, Fas-PE, FasL-PE, CD11b-PerCP-Cy5.5, CD8a-FITC, 7-AAD, and Annexin-V-FITC. Flow cytometry analysis was carried out using a BD FACS (BD Biosciences).
2.4. ELISA. Mouse and human CXCL1 ELISA kit (R\&D systems) were used to determine the concentrations of CXCL1 in cell culture supernatant or serum from tumor-bearing mice according to the manufacturer's instructions.

2.5. $q R T-P C R$. Total mRNA of 3LL cells was extracted with Trizol reagent (Invitrogen) and then subjected to reverse transcribed by using M-MLV reverse transcribed kit (Takara). cDNA was amplified by ABI7300 Detection System (Applied Biosystems) using SYBR Green PCR kit (Takara). Levels of CXCL1 were normalized by the levels of $\beta$-actin in each individual sample. Specific primers were as follows:

\section{$\mathrm{m} \beta$-actin: forward ( $5^{\prime}$-AGTGTGACGTTGACATC- CGT- $3^{\prime}$ ), \\ $\mathrm{m} \beta$-actin: reverse $\left(5^{\prime}\right.$-GCAGCTCAGTAACAGTCC- GC- $3^{\prime}$ ), \\ mCXCL1: forward ( $5^{\prime}$-GTCATAGCCACACTCAA- GAA $\left.-3^{\prime}\right)$, \\ mCXCL1: reverse (5'-AGACAGGTGCCATCA- GAG- $\left.3^{\prime}\right)$.}

2.6. Chemotaxis Assay. Cell migration was estimated by using a pore size of $3 \mu \mathrm{m}$ transwell chambers Matrigel (BD Biosciences, Bedford, MA, USA). $2 \times 10^{6}$ cells isolated from spleen and peripheral blood in $200 \mu \mathrm{L}$ of serum free medium were added into the upper chamber, and $600 \mu \mathrm{L}$ of cell culture supernatant from $3 \mathrm{LL} / \mathrm{NC}$, 3LL/shCXCL1, or medium control was added into bottom chamber. After incubating for $4 \mathrm{~h}$, the cells phenotype on the bottom was analyzed by flow cytometric analysis.

2.7. Tumor-Bearing Model. $5 \times 10^{5} 3 \mathrm{LL} / \mathrm{shCXCL1}$ cells or 3LL/NC cells were injected subcutaneously in the abdomen of $\mathrm{C} 57 \mathrm{BJ} / 6 \mathrm{~L}$ mice, tumor volume $(\mathrm{V})$ was measured twice a week and calculated by using the formula $0.5 \times$ [Length $\times$ Width ${ }^{2}$.

2.8. Immunofluorescence (IF). $\mathrm{CD} 1 \mathrm{~b}^{+} \mathrm{Ly}_{6 \mathrm{G}}^{+}$neutrophils in tumor tissue sections from tumor-bearing mice were analyzed by immunofluorescence staining. Ly6G antibody was used at the dilution of $1: 50$. The fluorescent-labeled second antibodies were used at the dilution of $1: 100$. Digital imaging was carried out using the software LASV4.5 (Leica DM 2000).

2.9. Immunohistochemistry (IHC). Five-micrometer thick sections were cut from formalin-fixed and paraffinembedded tissue specimens and put onto slides; sections were deparaffinized through alcohol gradients and rehydrated to water. Antigens were retrieved by using Citrate $\mathrm{pH} 6.0$ buffer in thermostatic bath at $100^{\circ} \mathrm{C}$ for 5 minutes. Tissue sections were incubated with primary anti-mouse Ly6G (Biolegend) at the dilution of 1:50 or anti-mouse MPO (Abcam) at the dilution of $1: 200$. Rabbit polyclonal IgG (DAKO) was used as negative control instead of primary antibody. Digital imaging was examined using the software LAS V4.5 (Leica DM 2000). 
2.10. Coculture System. TANs were isolated from tumor tissues derived from $3 \mathrm{LL} / \mathrm{NC}$ tumor-bearing mice; $\mathrm{CD} 4^{+}$ $\mathrm{T}$ cells were isolated from the spleens of naive mice. Cell sorting were carried out by using MACS system (Miltenyi Biotech). Splenic CD $4^{+} \mathrm{T}$ cells $\left(5 \times 10^{4} /\right.$ well $)$ with or without neutrophils $\left(5 \times 10^{4} /\right.$ well $)$ were cocultured in precoated CD3 $(2 \mu \mathrm{g} / \mathrm{mL}) 24$-well plates with soluble CD28 $(2 \mu \mathrm{g} / \mathrm{mL})$ and murine recombinant IL-2 $(1 \mathrm{ng} / \mathrm{mL})$ for 3 days. $\mathrm{CD} 4^{+} \mathrm{T}$ cells number was counted by flow cytometry.

2.11. Statistic Analysis. All the statistics were analyzed with the assistance of Graphpad Prism 5.0. The comparisons between two groups were analyzed by unpaired Student's $t$ test.

\section{Results}

3.1. Increased Level of CXCL1 in Serum Is Mainly Derived from 3LL Cancer Cells In Vivo. Compared to naïve mice, serum levels of CXCL1 in 3LL lung cancer bearing mice were significantly increased (Figure 1(a)). To examine the source of serum CXCL1 in 3LL tumor-bearing mice, we first examined the expression and secretion of CXCL1 in 3LL cells and found that 3LL cells constitutively secreted and expressed high level of CXCL1 (Figures 1(b) and 1(c)). In addition, we found the human non-small lung carcinoma cell A549 also secreted higher levels of CXCL1 (Figure 1(d)). However, the mouse epithelial cell line MLE did not secrete CXCL1 (Figure 1(d)), suggesting lung cancer cells could express and secrete higher levels of CXCL1. It has been reported that neutrophils are also able to express and produce significant amounts of CXCL1 when activated [24, 25]. Larger amounts of $\mathrm{Ly}_{6 \mathrm{G}}{ }^{+} \mathrm{MPO}^{+}$neutrophils were found in 3LL tumor tissues (Figure 1(e)). Then, we analyzed CXCL1 expression in TANs and 3LL tumor. The results showed that the expression of CXCL1 in 3LL tumor was higher than that in TANs or LPSstimulated TANs ( 9-fold) (Figure 1(f)). Furthermore, we knocked down CXCL1 expression in 3LL cells using CXCL1 targeted shRNA construct. The results showed that compared to negative control (NC), CXCL1 mRNA expression and secretion in CXCL1-silencing 3LL cells (shCXCL1) were significantly decreased (Figures 2(a) and 2(b)). Serum levels of CXCL1 were markedly decreased in the mice inoculated with shCXCL1 cells (Figure 2(c)). Taken together, these results demonstrate that 3LL-derived CXCL1 is the main source that contributes to the increased serum level of CXCL1 in vivo.

3.2. Knockdown of CXCL1 Expression in 3LL Cells Inhibits Tumor Growth In Vivo. Then, to investigate the roles of CXCL1 in lung cancer growth in vivo, 3LL transfected cells (NC or shCXCL1) were subcutaneously inoculated into C57BL/6J mice. The results showed that 3LL negative control cells (NC) grew aggressively in vivo, while knockdown CXCL1 expression in 3LL cells (shCXCL1) significantly attenuated tumor growth (Figures 2(d) and 2(e)). Furthermore, quantitative PCR analysis showed that CXCL1 expression in $3 \mathrm{LL} / \mathrm{shCXCL1}$ tumor tissues was significantly lower than that in 3LL/NC tumor tissues (Figure 2(f)). These results indicate that tumor-derived CXCL1 contributes to lung cancer growth in vivo.

3.3. Tumor-Derived CXCL1 Mediates TANs Infiltration. CXCL1 is an important chemokine that contributes to recruitment of CXCR2 expressing myeloid cells and neutrophils [7]. Myeloid cells in mice consist of $\mathrm{CD}_{11 b^{+}} \mathrm{Ly}_{6 \mathrm{C}^{+}}$monocytic cells and $\mathrm{CD} 11 \mathrm{~b}^{+} \mathrm{Ly}_{6 \mathrm{G}^{+}}$neutrophils/granulocytic cells [26]. Flow cytometric analysis showed that the frequency of $\mathrm{CD}_{11 b^{+}} \mathrm{Ly} 6 \mathrm{G}^{+}$neutrophils in the circulation of mice inoculated 3LL/shCXCL1 $(44.6 \% \pm 4.45 \%)$ was significantly decreased compared to mice inoculated with $3 \mathrm{LL} / \mathrm{NC}(57.7 \% \pm 1.8 \%)$ (Figures $3(\mathrm{a})$ and $3(\mathrm{~b}))$. However, $\mathrm{CD}_{11 \mathrm{~b}}{ }^{+} \mathrm{Ly}_{6 \mathrm{G}}{ }^{+}$neutrophils counts in bone marrow were similar (NC versus shCXCL1; $41.88 \% \pm 3.7 \%$ versus $53 \% \pm 3.82 \%$ ) (Figure $3(\mathrm{c})$ ). In addition, $\mathrm{CD} 1 \mathrm{~b}^{+} \mathrm{Ly}_{6 \mathrm{G}}{ }^{+}$neutrophils counts in spleen of mice inoculated with $3 \mathrm{LL} / \mathrm{NC}$ tumor cells did not profoundly change compared to mice inoculated with $3 \mathrm{LL} / \mathrm{shCXCL1}$ tumor cells (NC versus shCXCL1; $6.31 \% \pm 1.55 \%$ versus $5.34 \% \pm 1.65 \%$ ) (Figure 3(d)). IHC staining of Ly6G showed that the number of $\mathrm{Ly}_{6} \mathrm{G}^{+}$neutrophils in tumor tissues from mice inoculated with $3 \mathrm{LL} / \mathrm{NC}$ was higher than that in $3 \mathrm{LL} / \mathrm{shCXCL1}$ bearing mice (Figures $3(\mathrm{e})$ and $3(\mathrm{f})$ ). As myeloperoxidase (MPO) is signature marker of neutrophils existing in the granules of neutrophils [27], the result showed that there were more $\mathrm{MPO}^{+}$TANs from mice inoculated with $3 \mathrm{LL} / \mathrm{NC}$ than that from mice inoculated with 3LL/shCXCL1 (Figures 3(g) and 3(h)). Furthermore, using a transwell system, the accumulation of $\mathrm{CD}_{11 b^{+}} \mathrm{Ly}_{6 \mathrm{G}}{ }^{+}$ neutrophilsby CXCL1 in vitro was detected. The results showed that knockdown of CXCL1 expression in 3LL cells markedly reduced the number of chemoattracted neutrophils (chemoattracted neutrophils counts isolated from spleen: $3 \mathrm{LL} / \mathrm{NC}$ medium versus $3 \mathrm{LL} /$ shCXCL1 medium $31784 \pm 5904$ versus $1804 \pm 582$ ) (chemoattracted neutrophils counts isolated from blood: $3 \mathrm{LL} / \mathrm{NC}$ medium versus 3LL/shCXCL1 medium $182502 \pm 13119$ versus $7992 \pm 5763$ ) (Figure 3(i)). These results demonstrate that tumor-derived CXCL1 promotes neutrophils recruitment in vitro and in vivo.

3.4. Tumor-Infiltrated Neutrophils Inhibit T Cell-Mediated Anti-Tumor Function In Vitro and In Vivo. Previous study reported that TANs exhibited protumor phenotype by suppressing activation of $\mathrm{CD}^{+} \mathrm{T}$ cells in lung cancer [28]. So, we detected the number of effector $\mathrm{T}$ cells in spleen and tumor tissues derived from tumor-bearing mice. The results showed increased number of both $\mathrm{CD} 3^{+} \mathrm{CD} 4^{+}$and $\mathrm{CD} 3^{+} \mathrm{CD} 8^{+} \mathrm{T}$ cells in spleen and tumor tissues in 3LL/shCXCL1 group compared to 3LL/NC control group (Figures 4(a) and 4(b)), suggesting that the higher density of neutrophils was paralleled with the decreased $\mathrm{T}$ cells number in lung cancer. It has been reported that Fas/FasL expression by neutrophils can directly regulate $\mathrm{CD}^{+} \mathrm{T}$ cells infiltration [29]. We analyzed the expression of Fas/FasL in splenic neutrophils or TANs. As shown in Figure 4(c), splenic neutrophils expressed lower levels of Fas/FasL; however, tumor infiltrated neutrophils derived from both 3LL/NC and 3LL/shCXCL1 bearing mice 


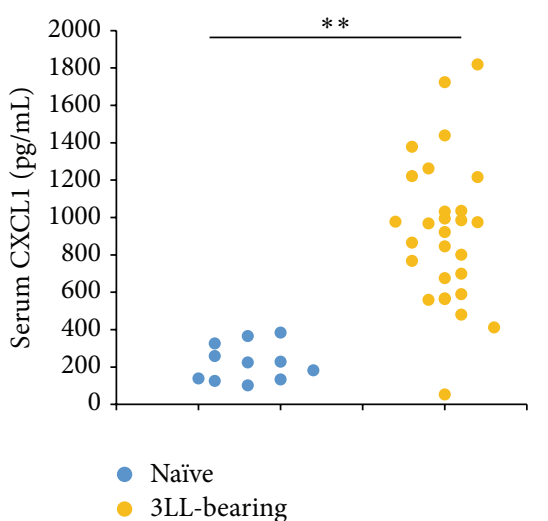

(a)

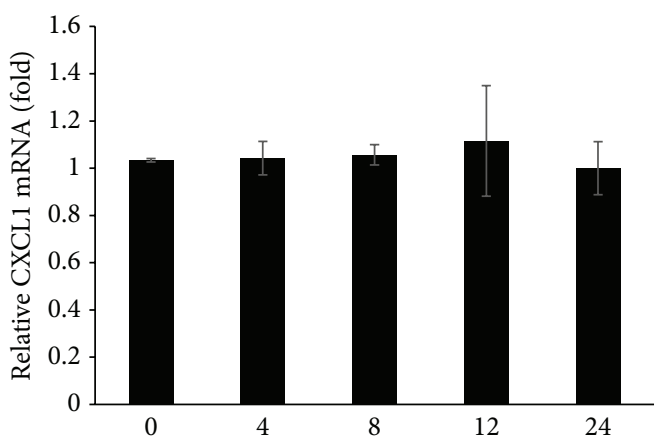

(h)

(c)
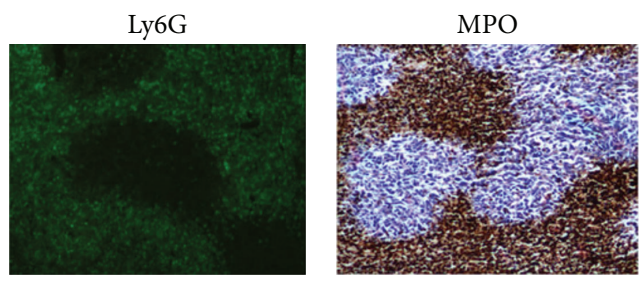

Tumor tissue

(e)

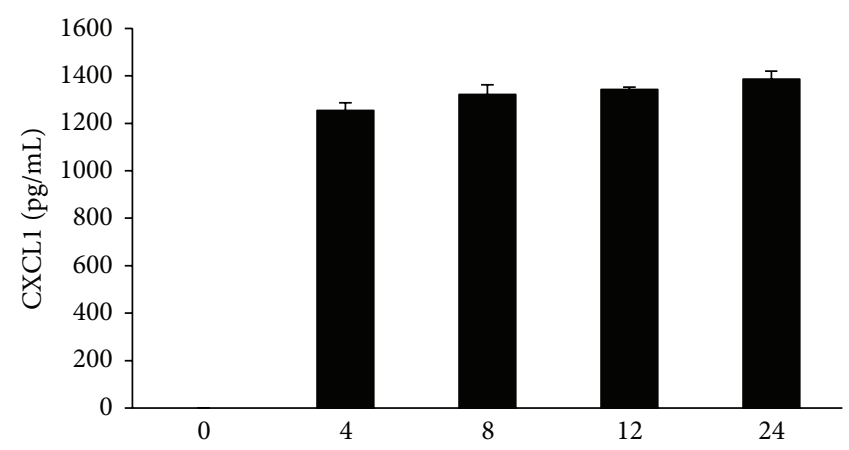

(h)

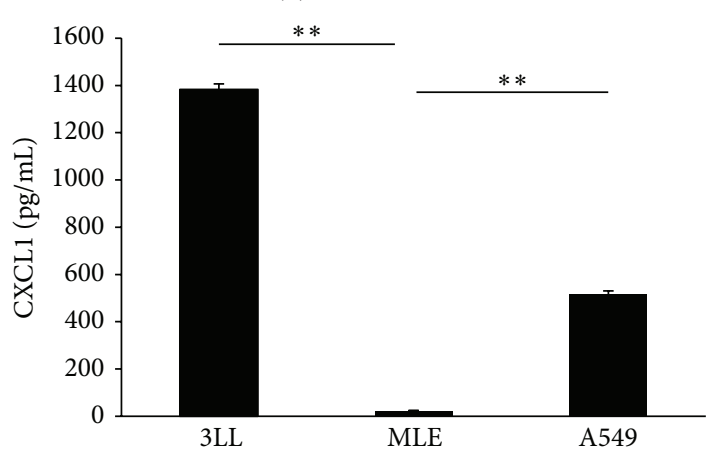

(d)

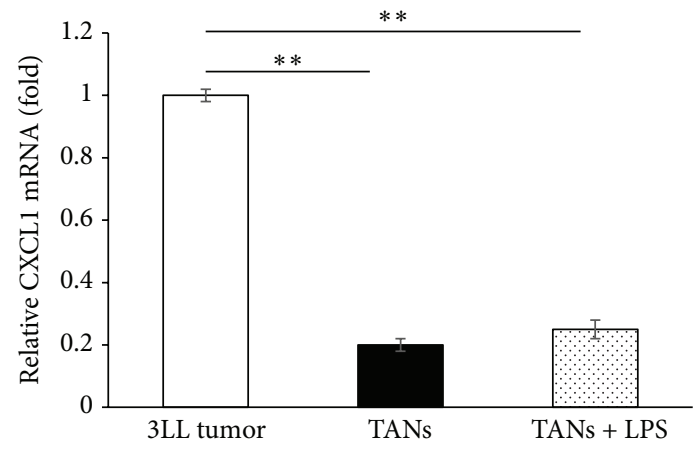

(f)

FIGURE 1: Expression and secretion of CXCL1 in vitro and in vivo. (a) Levels of CXCL1 in the serum of naive mice $(n=11)$ or 3LL tumorbearing mice $(n=27)$ were measured by ELISA at 14 days after tumor inoculation. Each dot represents an individual mouse. (b) CXCL1 protein levels in the 3LL culture supernatants were determined by ELISA. (c) mRNA expression of CXCL1 in 3LL cells was measured by quantitative RT-PCR. (d) ELISA analysis of CXCL1 production in Lewis lung carcinoma cell line 3LL, mouse epithelial cell line MLE, and human non-small lung carcinoma cell line A549. (e) $\mathrm{Ly}_{6 \mathrm{G}^{+}} \mathrm{MPO}^{+}$neutrophils in 3LL tumor tissues were determined by IF and IHC. (f) Quantitative RT-PCR analysis of CXCL1 expression in 3LL tumor cells and TANs (sorted from 3LL tumor tissues) stimulated with or without LPS $(100 \mathrm{ng} / \mathrm{mL})$ for 6 hours. ${ }^{* *} p<0.01$; data are shown as mean \pm SD.

expressed higher levels of Fas/FasL. Flow cytometric analysis demonstrated that the number of apoptotic/necrotic $\mathrm{CD} 4^{+}$ $\mathrm{T}$ cells and $\mathrm{CD}^{+} \mathrm{T}$ was lower in 3LL/shCXCL1 group compared to 3LL/NC group (Figure 4(c)). Furthermore, to determine the effect of TANs on proliferation of $\mathrm{T}$ cells, we isolated TANs in tumor tissues from 3LL tumorbearing mice. TANs significantly inhibited mature dendritic cells- (mDC-) mediated $\mathrm{CD}^{+} \mathrm{T}$ proliferation in vitro (Figure 4(e)). Consistently, TANs suppressed $\mathrm{CD}^{+} \mathrm{T}$ proliferation primed by anti-CD3 and CD28 (N/T cells, TANs/T cells versus T cells; $5612.3 \pm 1487.4,3592 \pm 1122.5$, versus $6652.7 \pm 764.9$ ) (Figure 4(f)). These results suggest that tumor infiltrated neutrophils could inhibit the proliferation and induce apoptosis/necrosis of T cells. 


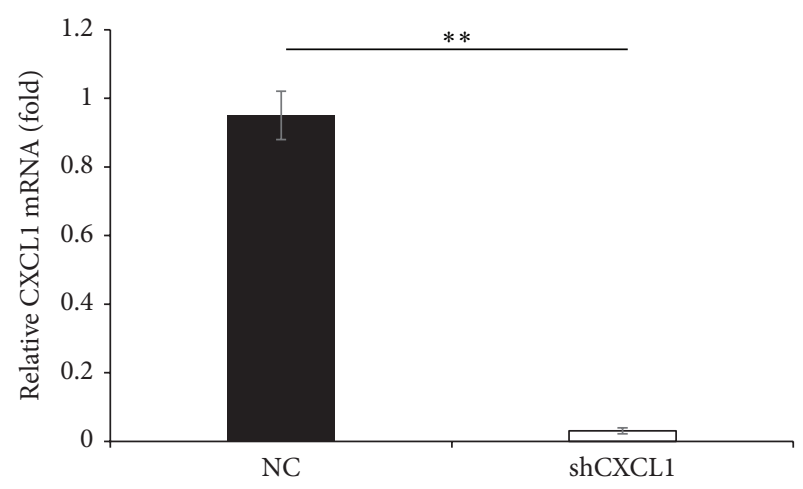

(a)

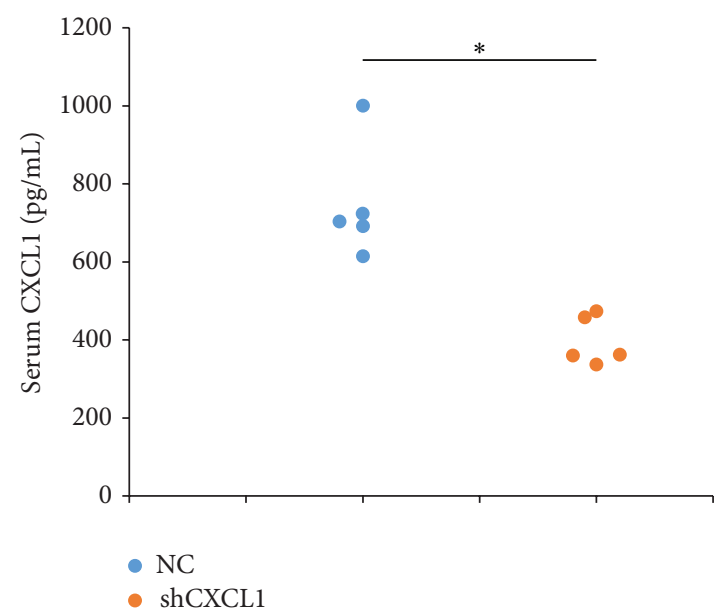

(c)

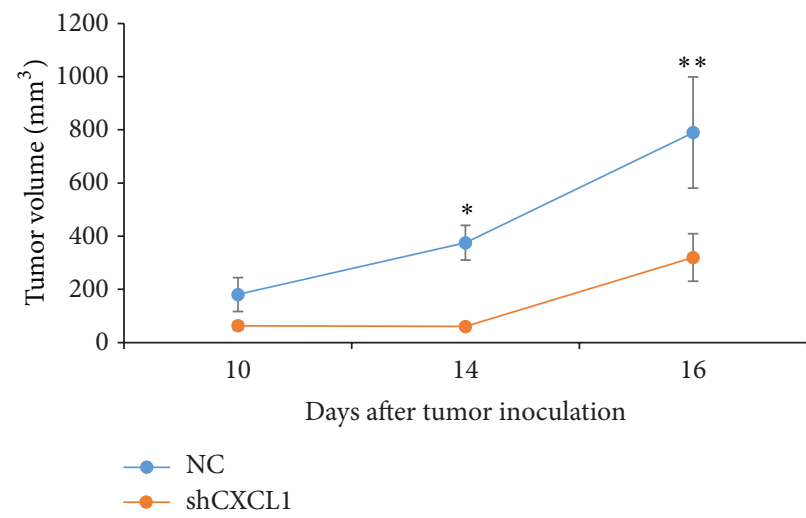

(e)

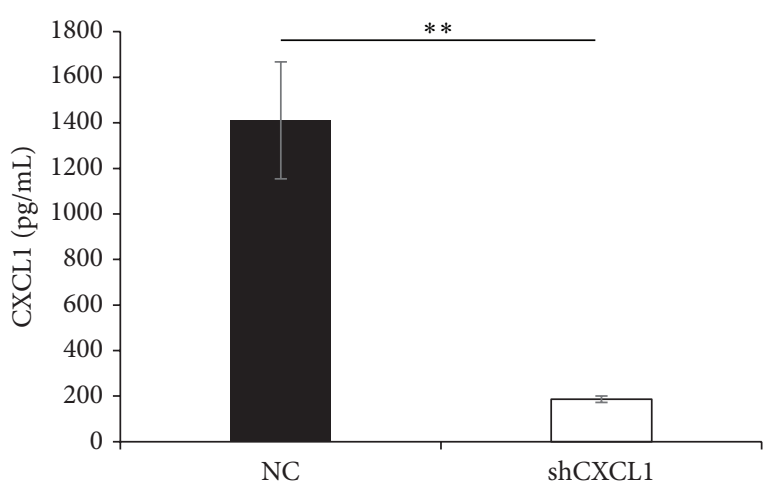

(b)

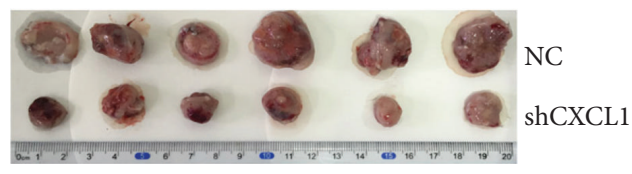

(d)

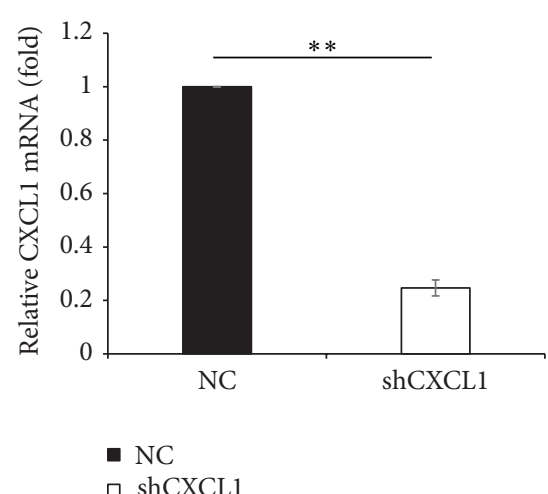

(f)

FIGURE 2: Ablation of CXCL1 in 3LL cells limits tumor growth in vivo. (a) 3LL cells were stable transfected with negative control shRNA (NC) or specific CXCL1 shRNA (shCXCL1); CXCL1 mRNA expression was measured by quantitative RT-PCR. (b) Protein levels of CXCL1 in the 3LL/NC and 3LL/shCXCL1 supernatants were measured by ELISA. (c) Serum levels of CXCL1 from 3LL/NC or 3LL/shCXCL1 bearing mice were measured by ELISA. Each dot represents an individual mouse. (d) Primary tumors excised from 3LL/NC bearing mice and 3LL/shCXCL1 bearing mice at day 16 after tumor inoculation. (e) Growth of NC and shCXCL1 tumors was monitored for 16 days after cell inoculations. (f) CXCL1 mRNA expression in tumor tissues derived from 3LL/NC or 3LL/shCXCL1 tumor-bearing mice was examined by quantitative RT-PCR. ${ }^{*} p<0.05,{ }^{* *} p<0.01$. Results are shown as mean \pm SD.

\section{Discussion}

Proinflammatory and chemokine factors play a prominent role in lymphocyte homing and migration [30-32]. Accumulating evidence demonstrated that tumor-derived chemokines modified the compartment of myeloid cells in the tumor microenvironment. CCL2 induced infiltration of regulatory dendritic cells and regulatory $\mathrm{T}$ cells in the tumor microenvironment [33], CXCL5/CXCR2 axis mediates the accumulation of $\mathrm{CXCR}^{+}$MDSCs [34], $\mathrm{CXCR}^{-/-}$mice 

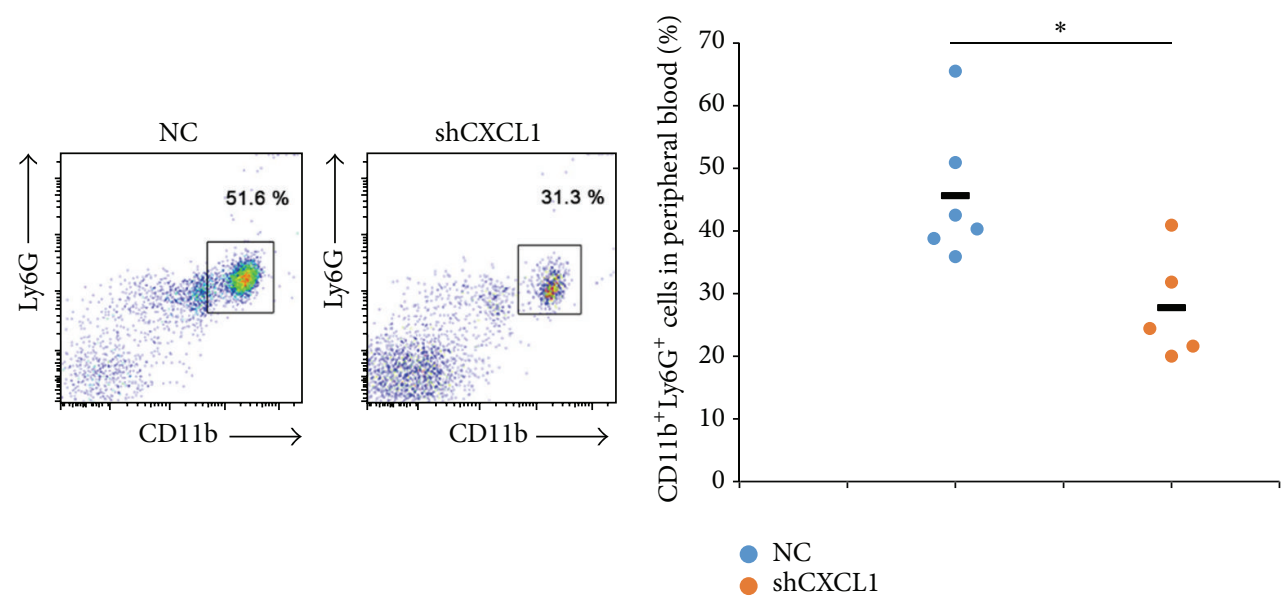

(a)

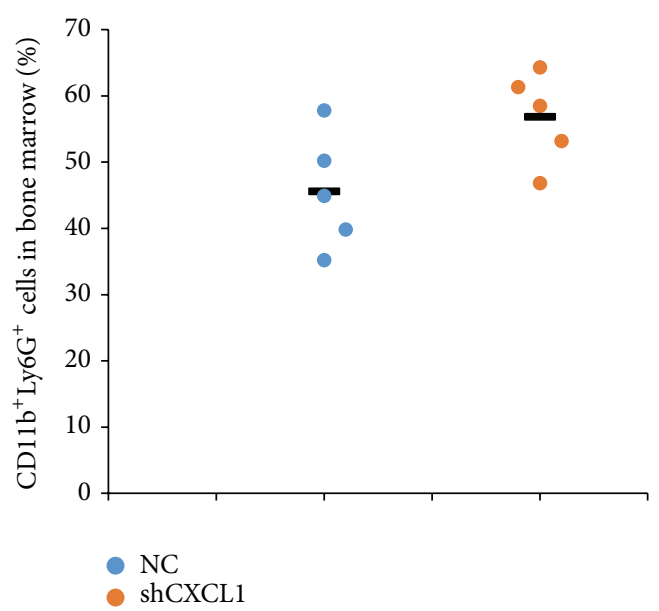

(c)
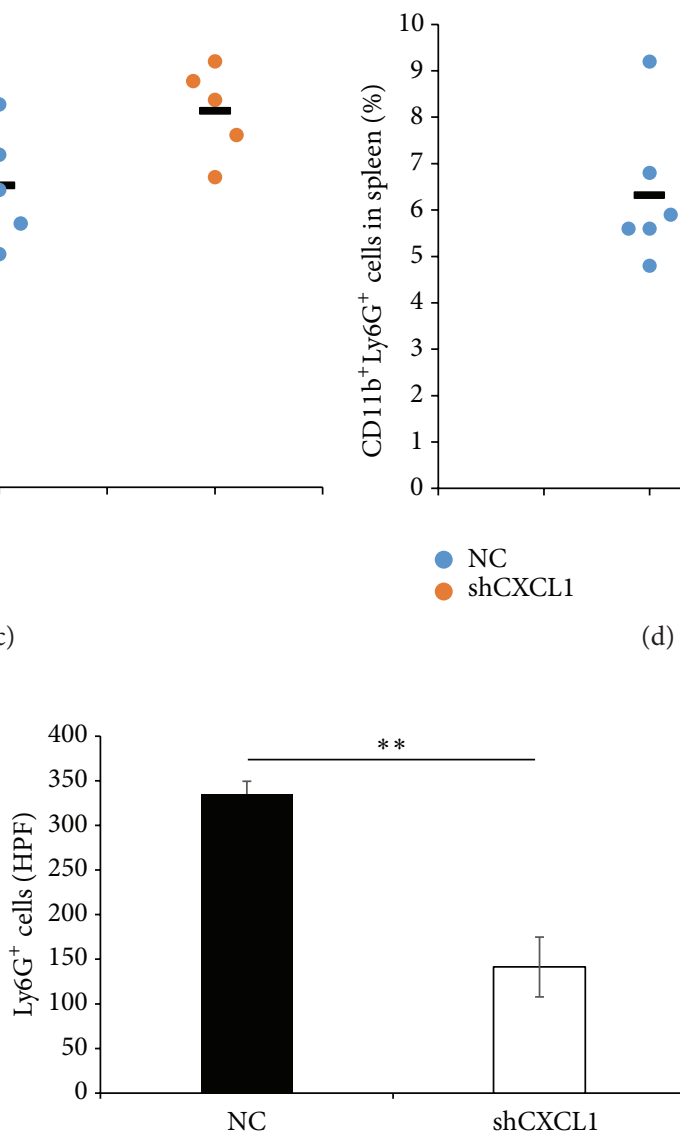

(e)

(f)

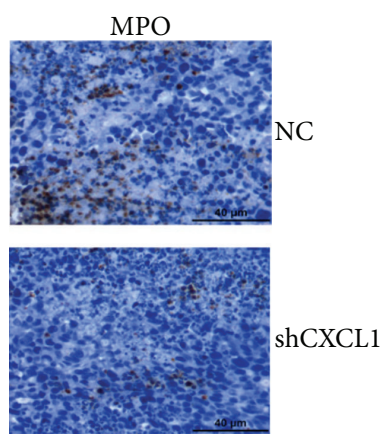

(g)

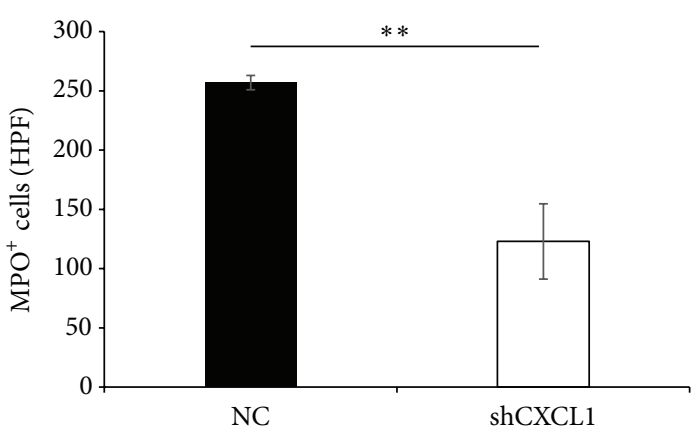

(h)

Figure 3: Continued. 


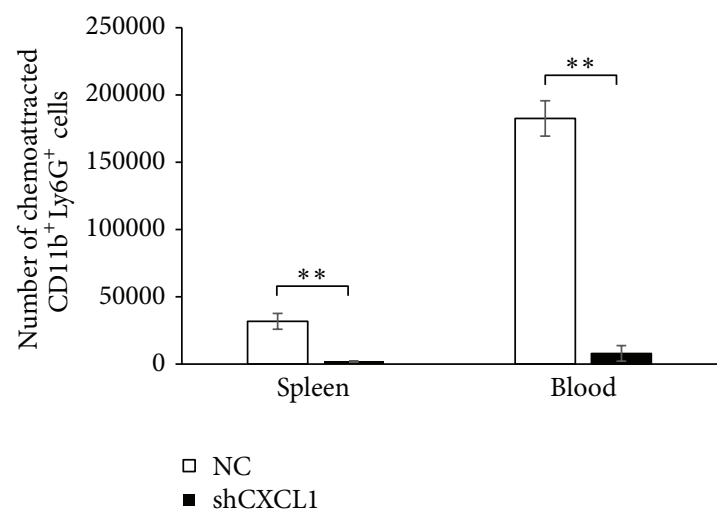

(i)

FIGURE 3: Knockdown of CXCL1 expression in 3LL cells decreases the number of neutrophils in vivo. $5 \times 10^{5} 3 \mathrm{LL} / \mathrm{NC}$ or $3 \mathrm{LL} / \mathrm{shCXCL1}$ cells were inoculated subcutaneously (s.c.) into C57BL/6J mice. At day 16, mice were scarified. The CD11b ${ }^{+} \mathrm{Ly}_{6 \mathrm{G}^{+}}$neutrophils in peripheral blood were detected as described in the materials and methods. Representative flow cytometric graph (a) and percentage of $\mathrm{CD}_{11 b^{+}} \mathrm{Ly}_{6 \mathrm{G}}{ }^{+}$ neutrophils in peripheral blood (b) were analyzed. Each dot plot represents an individual mice; horizontal lines are shown as mean of each group. (c) Flow cytometric analysis of the frequency of CD11b ${ }^{+} \mathrm{Ly}_{6} \mathrm{G}^{+}$neutrophils in bone marrow from mice inoculated with $3 \mathrm{LL} / \mathrm{NC}$ or 3LL/shCXCL1. (d) Flow cytometric analysis of the frequency of CD11b ${ }^{+} \mathrm{Ly}_{6 \mathrm{G}^{+}}$neutrophils in spleen from mice inoculated with $3 \mathrm{LL} / \mathrm{NC}$ or $3 \mathrm{LL} / \mathrm{shCXCL1}$ tumor cells. (e, $\mathrm{f}, \mathrm{g}$, and h) IHC staining of $\mathrm{Ly}_{6 \mathrm{G}^{+}}$or $\mathrm{MPO}^{+}$cells in the tumor tissues from mice inoculated with $3 \mathrm{LL} / \mathrm{NC}$ or $3 \mathrm{LL} / \mathrm{shCXCL1}$ tumor cells. IHC staining quantification of $\mathrm{Ly}_{6 \mathrm{G}}{ }^{+}$(f) or $\mathrm{MPO}^{+}$(h) cells (per high-power field, HPF). Scale bars, $20 \mu \mathrm{m}$ or $40 \mu \mathrm{m}$. (i) Neutrophils were isolated from spleen or peripheral blood derived from tumor-bearing mice and the chemoattracted CD11b ${ }^{+} \mathrm{Ly}_{6 \mathrm{G}}{ }^{+}$ neutrophils were analyzed towards the condition supernatant from NC and shCXCL1 tumor cells by in vitro transwell assay. ${ }^{*} p<0.05$, ${ }^{* *} p<0.01$.

were resistance to colitis-associated cancer formation by inhibiting MDSCs accumulation in the mucosa [15], and silence of CXCL1/2 expression in breast cancer decreased the infiltration of myeloid cells in the tumor microenvironment [17]. However, there is little evidence directly elucidating the function of tumor-derived CXCL1 on the migration of neutrophils/granulocytic cells. In this study, we demonstrated that 3LL tumor-derived chemokine CXCL1 regulated the composition of immune cells in tumor microenvironment. Knockdown of CXCL1 in 3LL cells resulted in decreased number of TANs, paralleled by increased number of $\mathrm{CD} 4^{+}$ $\mathrm{T}$ and $\mathrm{CD}^{+} \mathrm{T}$ cells. So, we demonstrated that tumorderived CXCL1 increased the number of $\mathrm{Ly}_{6 \mathrm{G}}{ }^{+}$neutrophils in the peripheral blood and tumor tissues. Silencing CXCL1 expression and secretion in 3LL cells markedly reduced the number of $\mathrm{Ly}_{6 \mathrm{G}}^{+}$neutrophils. Accordingly, CXCL1 deficiency in tumor significantly inhibited tumor growth in vivo. It has been well known that the increased number of neutrophils in peripheral blood is due to increased egress of bone marrow or prolonged life span [35]. So, we further examined the number and proportion of neutrophils in bone marrow. The results showed that there was no statistical significant difference of density of neutrophils in bone marrow between mice inoculated with $3 \mathrm{LL} / \mathrm{NC}$ and inoculated with 3LL/shCXCL1; however, there is approximately 1.3fold increase in neutrophil counts in the bone marrow of 3LL/shCXCL1 tumor-bearing mice, suggesting that CXCL1 maybe determine the efficiency of neutrophil egress from bone marrow. Although more evidence has identified the potential role of neutrophils in cancer progression. The roles of neutrophils in tumor microenvironment have not been well demonstrated [36]. Matrix metalloproteinases (MMPs), such as MMP9, mainly produced by neutrophils, have the ability to degrade the extracellular matrix (ECM), which contribute to carcinogenesis and tumor progression [37, 38]. However, neutrophils-derived MMP-8 was regarded as playing a protective role in tumor progression [39]. In a spontaneous metastasis model, deletion of neutrophils in tumor microenvironment decreased tumor angiogenesis and intravasation [40]. In addition, TANs promoted tumor invasion by releasing of ROS [41], growth factors such as hepatocyte growth factor (HGF) [42], and cytokines like oncostatin M [43]. Orchestrating antitumor immunity in the tumor environment is another important function of TANs. It was proven that neutrophils inhibited $\mathrm{T}$ cell proliferation by releasing intracellular arginase I in non-small lung cancer [44]. In mouse lung tumors, neutrophils depletion leaded to more activated $\mathrm{CD}^{+} \mathrm{T}$ cells intratumorally [28]. Multiple studies have demonstrated that TANs and lymphocytes ratio in tumor microenvironment could be a prognostic predictor in patients with various types of cancer, including lung carcinoma $[45,46]$ and esophageal carcinoma [47]. Our results demonstrated that the increased number of neutrophils was associated with decreased $\mathrm{T}$ cells number in tumor

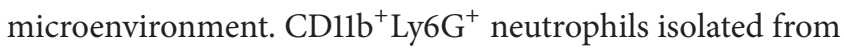
tumor-bearing mice expressed higher levels of Fas/FasL, which may be involved in $\mathrm{T}$ cells apoptosis. However, the expression levels of Fas/FasL in TANs did not depend on the CXCL1 expression in primary tumor cells. Which factor(s) in tumor microenvironment could enhance Fas/FasL expression in TANs needs to be further investigated. Beside Fas/FasL, TANs also expressed higher levels of MPO, and the number of $\mathrm{MPO}^{+}$neutrophils was less in $3 \mathrm{LL} /$ shCXCL1 tumor tissues than that in 3LL/NC tumor tissues. It had been 

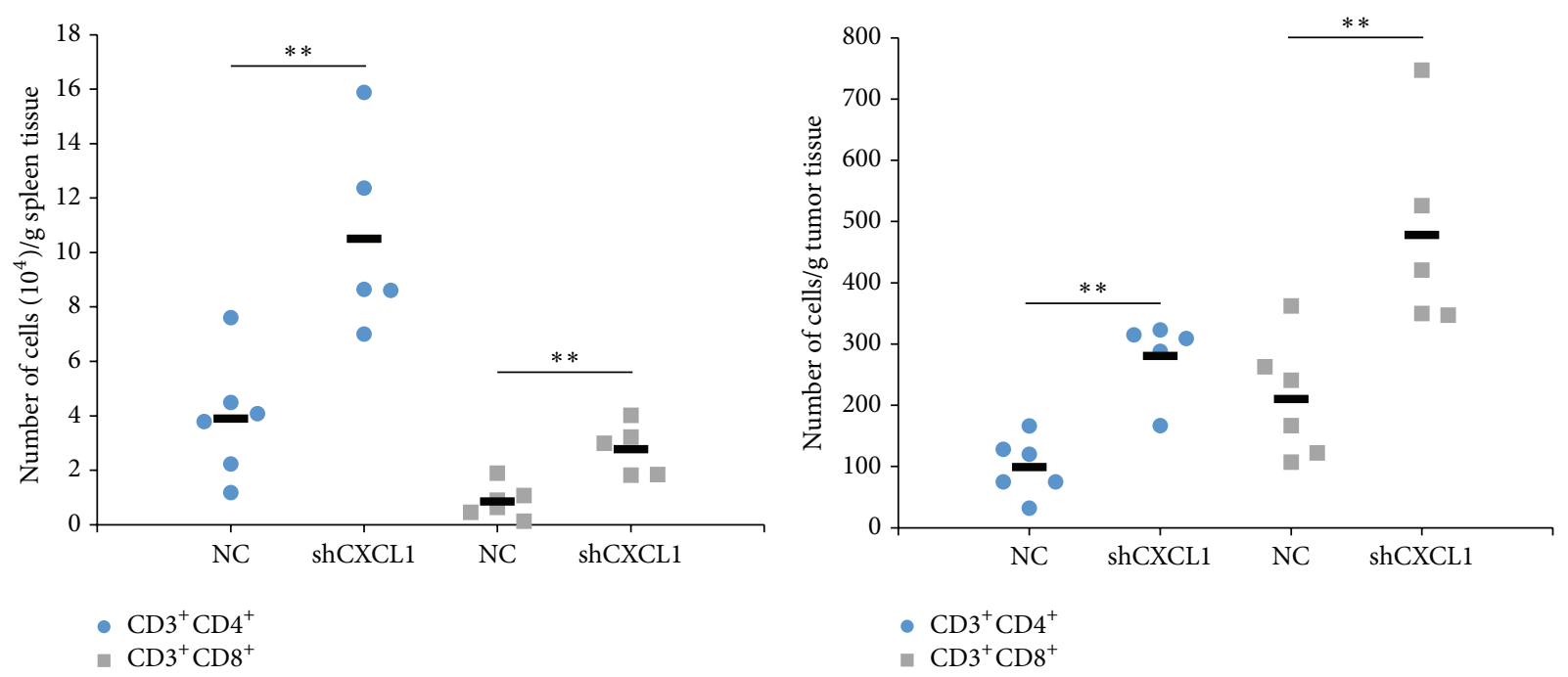

(a)

(b)
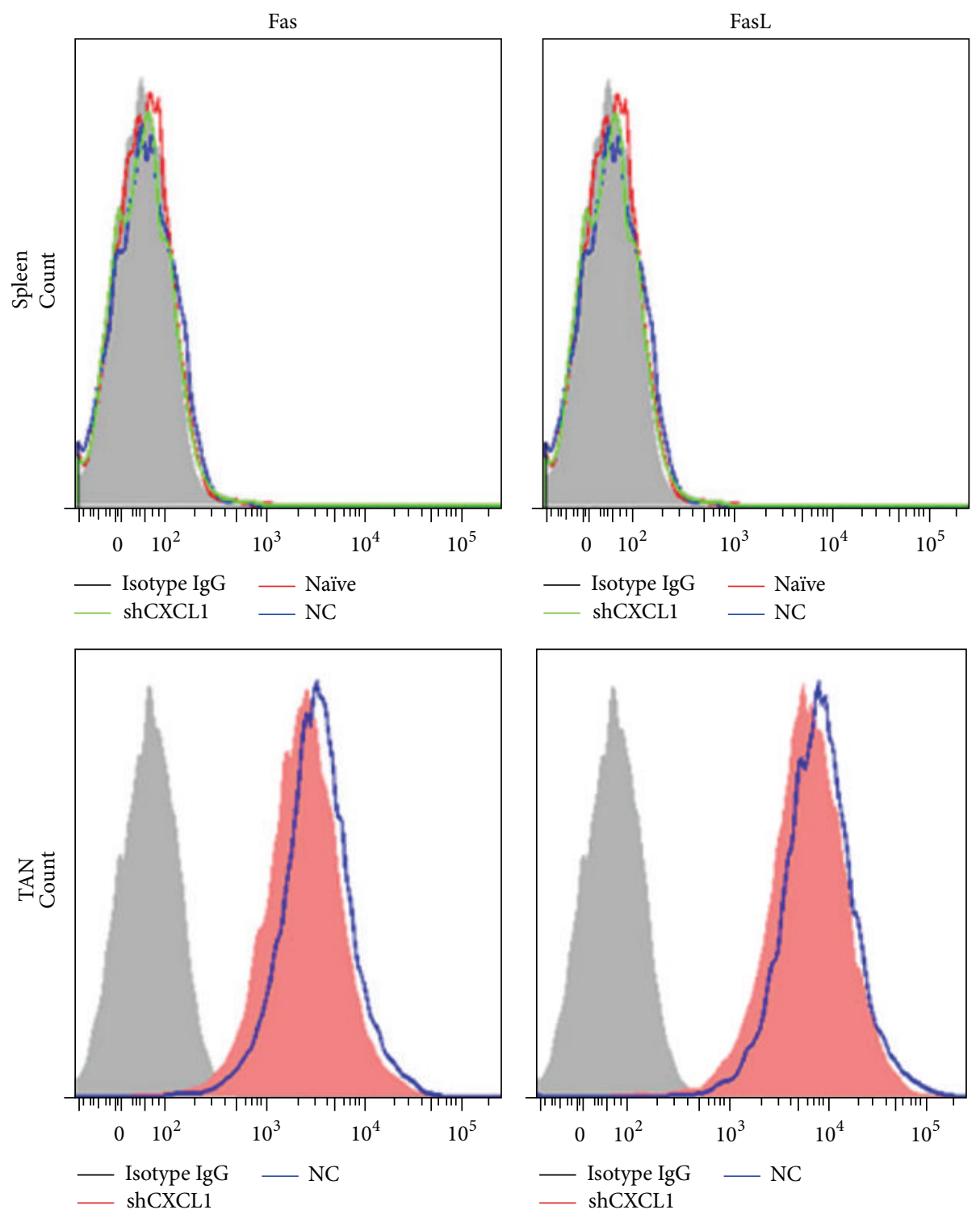

(c)

FIGURE 4: Continued. 

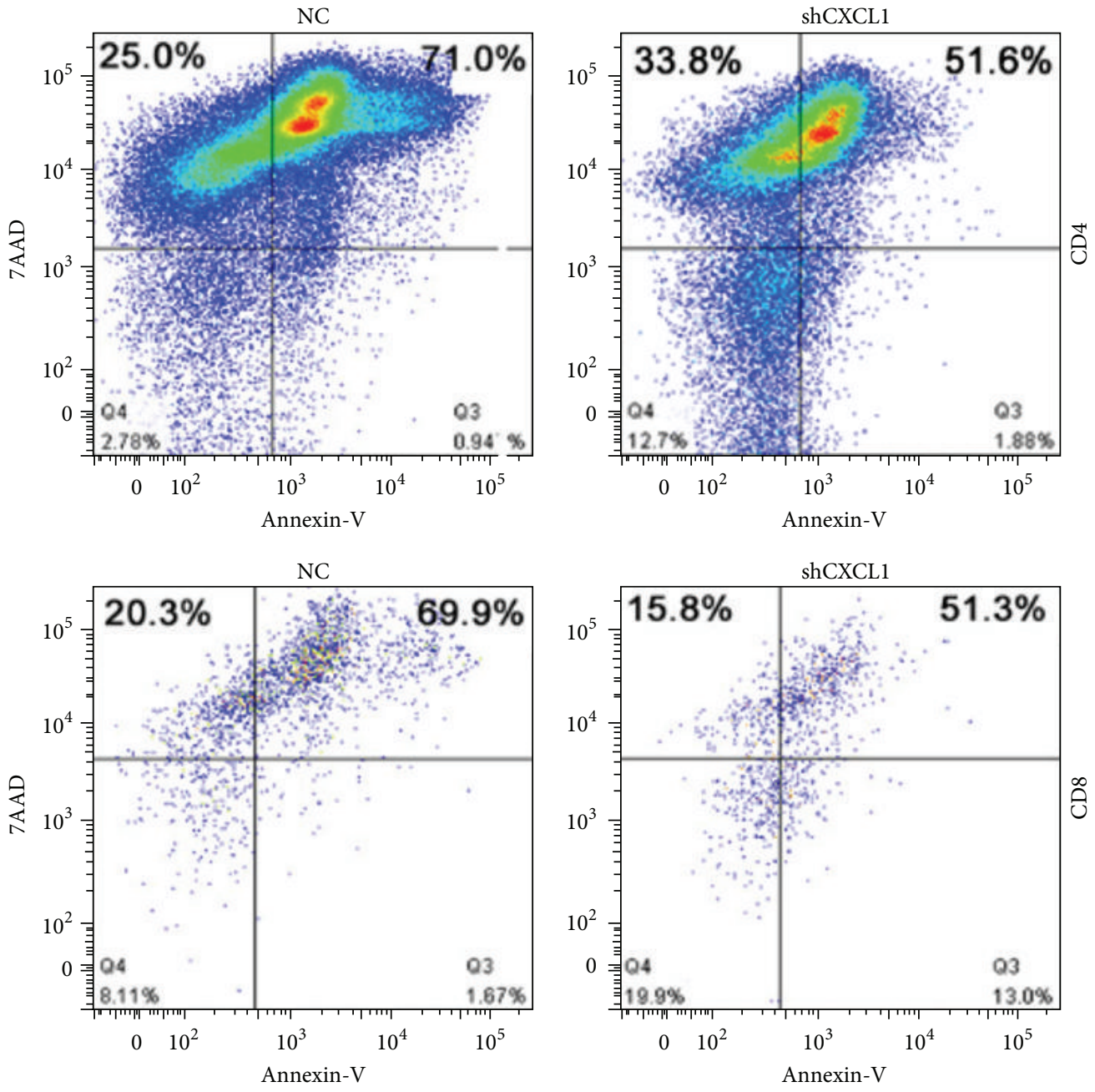

(d)

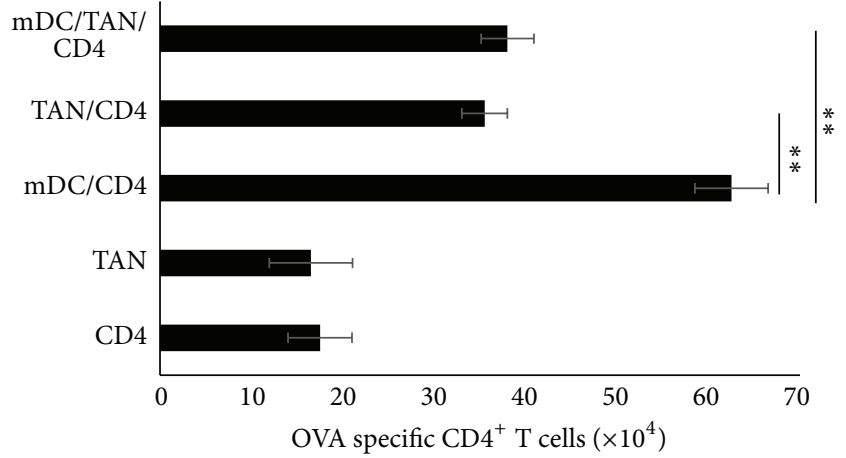

(e)

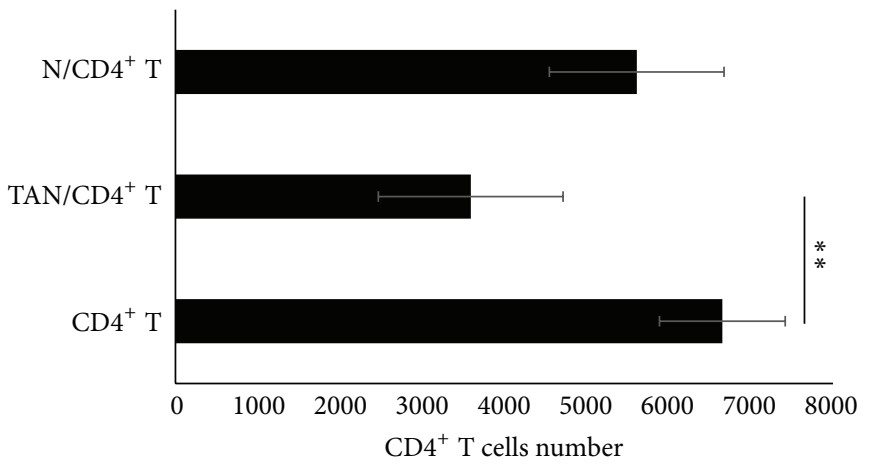

(f)

FIgure 4: Tumor-infiltrating neutrophils in tumor inhibit T cell proliferation. Number of $\mathrm{CD} 3^{+} \mathrm{CD} 4^{+}$and $\mathrm{CD} 3^{+} \mathrm{CD} 8^{+} \mathrm{T}$ cells in the spleen (a) and tumor tissues (b) at day 14 after tumor inoculation were analyzed by flow cytometric. (c) Fas/FasL expression on splenic CD11b ${ }^{+}$Ly6G $^{+}$ neutrophils or TANs from 3LL/NC bearing mice, 3LL/shCXCL1 bearing, or naïve mice were analyzed by cytometric analysis. (d) CD $4^{+} \mathrm{T}$ or $\mathrm{CD}^{+} \mathrm{T}$ cells derived from tumor tissues were stained with 7AAD and Annexin-V, flow cytometric analysis of apoptotic/necrotic CD $4^{+} \mathrm{T}$,

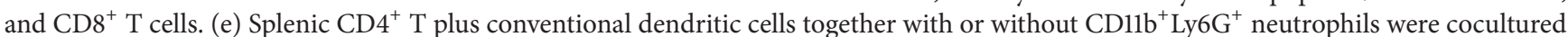
for 3 days with $10 \mu \mathrm{g} / \mathrm{mL}$ OVA; CD $4^{+}$T cells were counted by flow cytometry. (f) Splenic CD $4^{+} \mathrm{T}$ and TANs were cocultured for 3 days with anti-CD3 and anti-CD28 and IL-2, CD4 ${ }^{+}$T cells numbers were counted by flow cytometry. $\mathrm{N}$ (splenic neutrophils); TAN (tumor-associated neutrophils). ${ }^{* *} p<0.01$. Data are presented as means \pm SD. 
demonstrated that High $\mathrm{MPO}^{+}$cell infiltration in colorectal cancer was an independent favorable prognostic factor [48] and MPO inhibitor reduced lung carcinoma growth during the early stages of tumor progression [49], suggesting that $\mathrm{MPO}^{+}$neutrophil involved promoting lung cancer growth. Additionally, in our unpublished studies we demonstrated that TANs expressed higher levels of PDL1, which exhibited immunosuppressive function via inhibiting $\mathrm{CD} 4^{+} \mathrm{T}$ and $\mathrm{CD}^{+} \mathrm{T}$ cell proliferation, which maybe contribute to TANmediated suppression of $\mathrm{T}$ cells proliferation. In conclusion, 3LL tumor-derived CXCL1 contributes to TANs infiltration in lung cancer which promotes tumor growth.

\section{Abbreviations \\ MPO: Myeloperoxidase \\ TANs: Tumor-associated neutrophils \\ MDSCs: Myeloid-derived suppressive cells \\ mDC: Mature dendritic cells \\ HCC: Hepatocellular carcinoma \\ IF: Immunofluorescence \\ IHC: Immunohistochemistry.}

\section{Competing Interests}

All the authors declare that there is no conflict of interests.

\section{Authors' Contributions}

Ming Yuan and Ha Zhu contributed equally to this work.

\section{Acknowledgments}

This project was supported by grants from the National Key Basic Research Program of China (2014CB542102) and National Natural Science Foundation of China (31170844, 31570869).

\section{References}

[1] D. S. Mowls, D. R. McCaffree, and L. A. Beebe, "Trends in lung cancer incidence rates, Oklahoma 2005-2010,” PLoS ONE, vol. 10, no. 4, Article ID e0119251, 2015.

[2] S. Ueha, F. H. W. Shand, and K. Matsushima, "Myeloid cell population dynamics in healthy and tumor-bearing mice," International Immunopharmacology, vol. 11, no. 7, pp. 783-788, 2011.

[3] L. Strauss, S. Sangaletti, F. M. Consonni et al., "RORC1 regulates tumor-promoting 'emergency' granulo-monocytopoiesis," Cancer Cell, vol. 28, no. 2, pp. 253-269, 2015.

[4] M. Shen, P. Hu, F. Donskov, G. Wang, Q. Liu, and J. Du, “Tumorassociated neutrophils as a new prognostic factor in cancer: a systematic review and meta-analysis," PLoS ONE, vol. 9, no. 6, article e98259, 2014.

[5] K. Movahedi, M. Guilliams, J. Van Den Bossche et al., "Identification of discrete tumor-induced myeloid-derived suppressor cell subpopulations with distinct $\mathrm{T}$ cell suppressive activity," Blood, vol. 111, no. 8, pp. 4233-4244, 2008.
[6] S.-L. Zhou, Z. Dai, Z.-J. Zhou et al., "Overexpression of CXCL5 mediates neutrophil infiltration and indicates poor prognosis for hepatocellular carcinoma," Hepatology, vol. 56, no. 6, pp. 2242-2254, 2012.

[7] K. V. Sawant, R. Xu, R. Cox et al., "Chemokine CXCL1-mediated neutrophil trafficking in the lung: role of CXCR2 activation," Journal of Innate Immunity, vol. 7, no. 6, pp. 647-658, 2015.

[8] L. Raccosta, R. Fontana, D. Maggioni et al., "The oxysterol-cxcr2 axis plays a key role in the recruitment of tumor-promoting neutrophils," Journal of Experimental Medicine, vol. 210, no. 9, pp. 1711-1728, 2013.

[9] A. Viola, A. Sarukhan, V. Bronte, and B. Molon, "The pros and cons of chemokines in tumor immunology," Trends in Immunology, vol. 33, no. 10, pp. 496-504, 2012.

[10] K. J. Eash, A. M. Greenbaum, P. K. Gopalan, and D. C. Link, "CXCR2 and CXCR4 antagonistically regulate neutrophil trafficking from murine bone marrow," Journal of Clinical Investigation, vol. 120, no. 7, pp. 2423-2431, 2010.

[11] D. Wang, H. Wang, J. Brown et al., "CXCL1 induced by prostaglandin E2 promotes angiogenesis in colorectal cancer," Journal of Experimental Medicine, vol. 203, no. 4, pp. 941-951, 2006.

[12] G. Yang, D. G. Rosen, Z. Zhang et al., "The chemokine growth-regulated oncogene 1 (Gro-1) links RAS signaling to the senescence of stromal fibroblasts and ovarian tumorigenesis," Proceedings of the National Academy of Sciences of the United States of America, vol. 103, no. 44, pp. 16472-16477, 2006.

[13] Z. Cao, B. Fu, B. Deng, Y. Zeng, X. Wan, and L. Qu, "Overexpression of Chemokine $(\mathrm{C}-\mathrm{X}-\mathrm{C})$ ligand 1 (CXCL1) associated with tumor progression and poor prognosis in hepatocellular carcinoma," Cancer Cell International, vol. 14, no. 1, article 86, 2014.

[14] L. Li, L. Xu, J. Yan et al., "CXCR2-CXCL1 axis is correlated with neutrophil infiltration and predicts a poor prognosis in hepatocellular carcinoma," Journal of Experimental and Clinical Cancer Research, vol. 34, no. 1, article 129, 2015.

[15] H. Katoh, D. Wang, T. Daikoku, H. Sun, S. K. Dey, and R. N. DuBois, "CXCR2-expressing myeloid-derived suppressor cells are essential to promote colitis-associated tumorigenesis," Cancer Cell, vol. 24, no. 5, pp. 631-644, 2013.

[16] H. Ogata, A. Sekikawa, H. Yamagishi et al., "GRO $\alpha$ promotes invasion of colorectal cancer cells," Oncology Reports, vol. 24, no. 6, pp. 1479-1486, 2010.

[17] S. Acharyya, T. Oskarsson, S. Vanharanta et al., "A CXCL1 paracrine network links cancer chemoresistance and metastasis," Cell, vol. 150, no. 1, pp. 165-178, 2012.

[18] K. Q. Han, X. Q. He, M. Y. Ma et al., "Targeted silencing of CXCL1 by siRNA inhibits tumor growth and apoptosis in hepatocellular carcinoma," International Journal of Oncology, vol. 47, no. 6, pp. 2131-2140, 2015.

[19] O. R. Bandapalli, F. Ehrmann, V. Ehemann et al., "Downregulation of CXCL1 inhibits tumor growth in colorectal liver metastasis," Cytokine, vol. 57, no. 1, pp. 46-53, 2012.

[20] J. Xu, C. Zhang, Y. He et al., "Lymphatic endothelial cell-secreted CXCL1 stimulates lymphangiogenesis and metastasis of gastric cancer," International Journal of Cancer, vol. 130, no. 4, pp. 787797, 2012.

[21] W.-L. Cheng, C.-S. Wang, Y.-H. Huang, M.-M. Tsai, Y. Liang, and K.-H. Lin, "Overexpression of CXCL1 and its receptor CXCR2 promote tumor invasion in gastric cancer," Annals of Oncology, vol. 22, no. 10, pp. 2267-2276, 2011. 
[22] Y. Zhang, Q. Liu, M. Zhang, Y. Yu, X. Liu, and X. Cao, "Fas signal promotes lung cancer growth by recruiting myeloidderived suppressor cells via cancer cell-derived PGE," Journal of Immunology, vol. 182, no. 6, pp. 3801-3808, 2009.

[23] J. Hou, Y. Zhou, Y. Zheng et al., "Hepatic RIG-I predicts survival and interferon- $\alpha$ therapeutic response in hepatocellular carcinoma," Cancer Cell, vol. 25, no. 1, pp. 49-63, 2014.

[24] S. Gasperini, F. Calzetti, M. P. Russo, M. De Gironcoli, and M. A. Cassatella, "Regulation of GRO $\alpha$ production in human granulocytes," Journal of Inflammation, vol. 45, no. 3, pp. 143151, 1995.

[25] F. Hayashi, T. K. Means, and A. D. Luster, "Toll-like receptors stimulate human neutrophil function,” Blood, vol. 102, no. 7, pp. 2660-2669, 2003.

[26] S. Ostrand-Rosenberg and P. Sinha, "Myeloid-derived suppressor cells: linking inflammation and cancer," Journal of Immunology, vol. 182, no. 8, pp. 4499-4506, 2009.

[27] M. van de Vyver, L. Engelbrecht, C. Smith, and K. H. Myburgh, "Neutrophil and monocyte responses to downhill running: intracellular contents of MPO, IL-6, IL-10, pstat3, and SOCS3," Scandinavian Journal of Medicine and Science in Sports, vol. 26, no. 6, pp. 638-647, 2016.

[28] Z. G. Fridlender, J. Sun, S. Kim et al., "Polarization of tumorassociated neutrophil phenotype by TGF- $\beta$ : 'N1' versus 'N2' TAN," Cancer Cell, vol. 16, no. 3, pp. 183-194, 2009.

[29] D. D. Kish, A. V. Gorbachev, N. Parameswaran, N. Gupta, and R. L. Fairchild, "Neutrophil expression of Fas ligand and perforin directs effector CD8 T cell infiltration into antigen-challenged skin," The Journal of Immunology, vol. 189, no. 5, pp. 2191-2202, 2012.

[30] P. G. Andres, P. L. Beck, E. Mizoguchi et al., "Mice with a selective deletion of the CC chemokine receptors 5 or 2 are protected from dextran sodium sulfate-mediated colitis: lack of CC chemokine receptor 5 expression results in a NK1.1+ lymphocyte-associated Th2-type immune response in the intestine," Journal of Immunology, vol. 164, no. 12, pp. 6303$6312,2000$.

[31] W. I. Khan, Y. Motomura, H. Wang et al., "Critical role of MCP-1 in the pathogenesis of experimental colitis in the context of immune and enterochromaffin cells," American Journal of Physiology-Gastrointestinal and Liver Physiology, vol. 291, no. 5, pp. G803-G811, 2006.

[32] H. Tokuyama, S. Ueha, M. Kurachi et al., "The simultaneous blockade of chemokine receptors CCR2, CCR5 and CXCR3 by a non-peptide chemokine receptor antagonist protects mice from dextran sodium sulfate-mediated colitis," International Immunology, vol. 17, no. 8, pp. 1023-1034, 2005.

[33] C. Kudo-Saito, H. Shirako, M. Ohike, N. Tsukamoto, and Y. Kawakami, "CCL2 is critical for immunosuppression to promote cancer metastasis," Clinical and Experimental Metastasis, vol. 30, no. 4, pp. 393-405, 2013.

[34] L. Yang, J. Huang, X. Ren et al., "Abrogation of TGF $\beta$ signaling in mammary carcinomas recruits Gr-1+CD11b+ myeloid cells that promote metastasis," Cancer Cell, vol. 13, no. 1, pp. 23-35, 2008.

[35] Y. Kobayashi, "Neutrophil biology: an update," EXCLI Journal, vol. 14, pp. 220-227, 2015.

[36] D. R. Powell and A. Huttenlocher, "Neutrophils in the tumor microenvironment," Trends in Immunology, vol. 37, no. 1, pp. 41$52,2016$.
[37] C. A. Dumitru, S. Lang, and S. Brandau, "Modulation of neutrophil granulocytes in the tumor microenvironment: mechanisms and consequences for tumor progression," Seminars in Cancer Biology, vol. 23, no. 3, pp. 141-148, 2013.

[38] L. M. Coussens, C. L. Tinkle, D. Hanahan, and Z. Werb, "MMP9 supplied by bone marrow-derived cells contributes to skin carcinogenesis," Cell, vol. 103, no. 3, pp. 481-490, 2000.

[39] C. Soria-Valles, A. Gutiérrez-Fernández, M. Guiu et al., "The anti-metastatic activity of collagenase- 2 in breast cancer cells is mediated by a signaling pathway involving decorin and miR-21," Oncogene, vol. 33, no. 23, pp. 3054-3063, 2014.

[40] E. M. Bekes, B. Schweighofer, T. A. Kupriyanova et al., "Tumorrecruited neutrophils and neutrophil TIMP-free MMP-9 regulate coordinately the levels of tumor angiogenesis and efficiency of malignant cell intravasation," The American Journal of Pathology, vol. 179, no. 3, pp. 1455-1470, 2011.

[41] N. Güngör, A. M. Knaapen, A. Munnia et al., "Genotoxic effects of neutrophils and hypochlorous acid," Mutagenesis, vol. 25, no. 2, pp. 149-154, 2010.

[42] M. Wislez, N. Rabbe, J. Marchal et al., "Hepatocyte growth factor production by neutrophils infiltrating bronchioloalveolar subtype pulmonary adenocarcinoma: role in tumor progression and death," Cancer Research, vol. 63, no. 6, pp. 1405-1412, 2003.

[43] M. M. Queen, R. E. Ryan, R. G. Holzer, C. R. Keller-Peck, and C. L. Jorcyk, "Breast cancer cells stimulate neutrophils to produce oncostatin M: potential implications for tumor progression," Cancer Research, vol. 65, no. 19, pp. 8896-8904, 2005.

[44] R. Rotondo, G. Barisione, L. Mastracci et al., "IL-8 induces exocytosis of arginase 1 by neutrophil polymorphonuclears in nonsmall cell lung cancer," International Journal of Cancer, vol. 125, no. 4, pp. 887-893, 2009.

[45] K. Kadota, J.-I. Nitadori, H. Ujiie et al., "Prognostic impact of immune microenvironment in lung squamous cell carcinoma: tumor-infiltrating $\mathrm{CD} 0^{+}$neutrophil/CD20 ${ }^{+}$lymphocyte ratio as an independent prognostic factor," Journal of Thoracic Oncology, vol. 10, no. 9, pp. 1301-1310, 2015.

[46] N. Dirican, Y. A. Karakaya, S. Gunes, F. T. Daloglu, and A. Dirican, "Association of intra-tumoral tumour-infiltrating lymphocytes and neutrophil-to-lymphocyte ratio is an independent prognostic factor in non-small cell lung cancer," The Clinical Respiratory Journal, 2015.

[47] T. Arigami, H. Okumura, M. Matsumoto et al., "Analysis of the fibrinogen and neutrophil-lymphocyte ratio in esophageal squamous cell carcinoma," Medicine, vol. 94, no. 42, Article ID e1702, 2015.

[48] R. A. Droeser, C. Hirt, S. Eppenberger-Castori et al., "High myeloperoxidase positive cell infiltration in colorectal cancer is an independent favorable prognostic factor," PLoS ONE, vol. 8, no. 5, Article ID e64814, 2013.

[49] A. L. Rymaszewski, E. Tate, J. P. Yimbesalu et al., "The role of neutrophil myeloperoxidase in models of lung tumor development," Cancers, vol. 6, no. 2, pp. 1111-1127, 2014. 


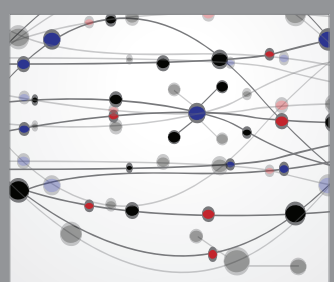

The Scientific World Journal
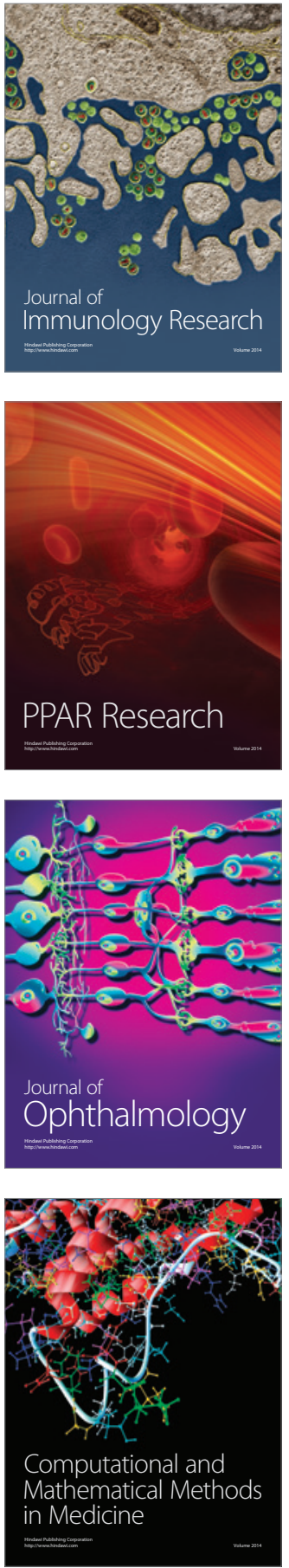

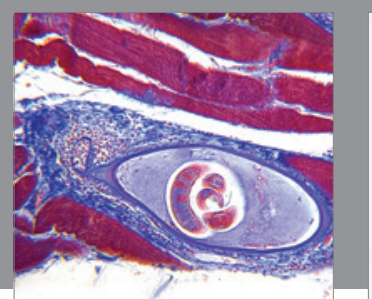

Gastroenterology Research and Practice

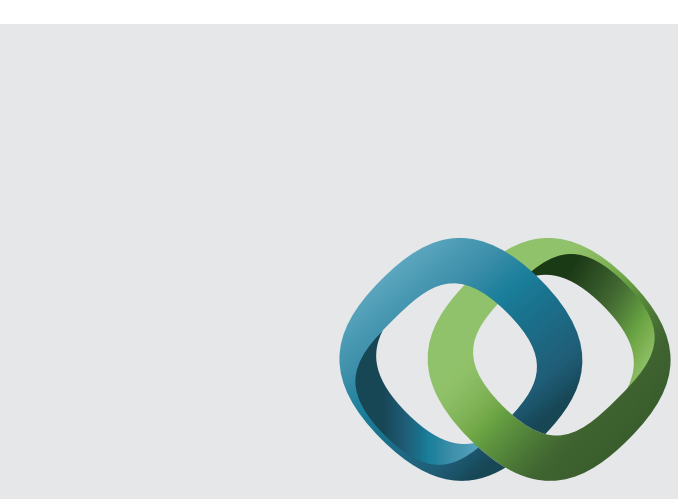

\section{Hindawi}

Submit your manuscripts at

http://www.hindawi.com
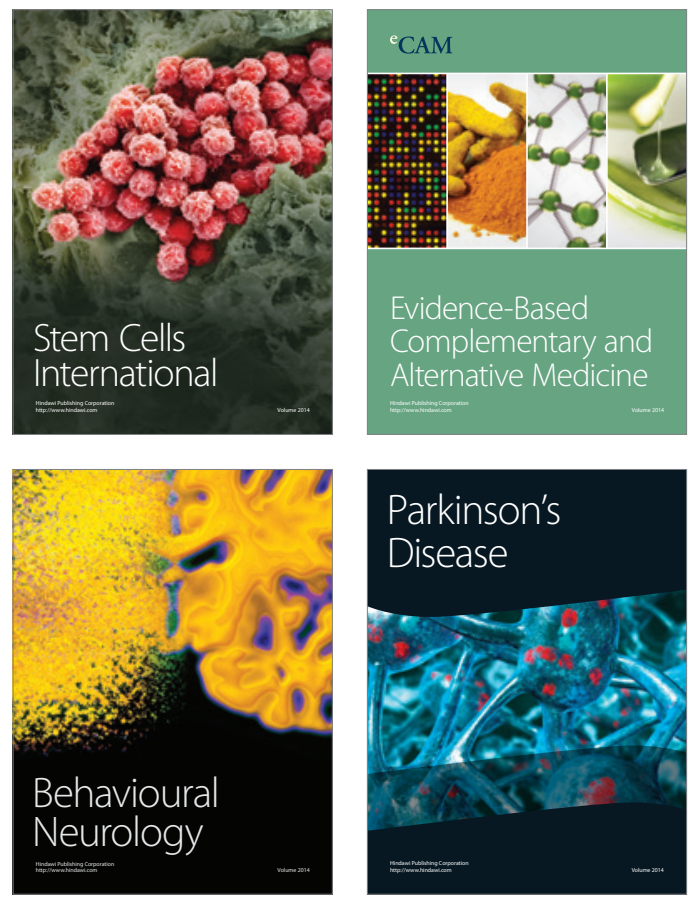
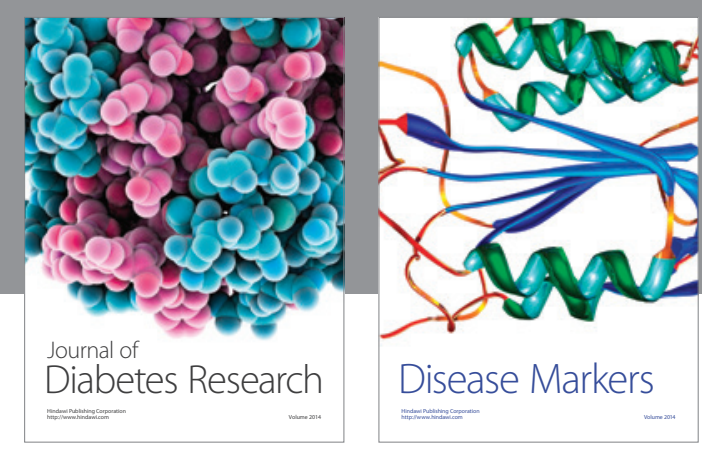

Disease Markers
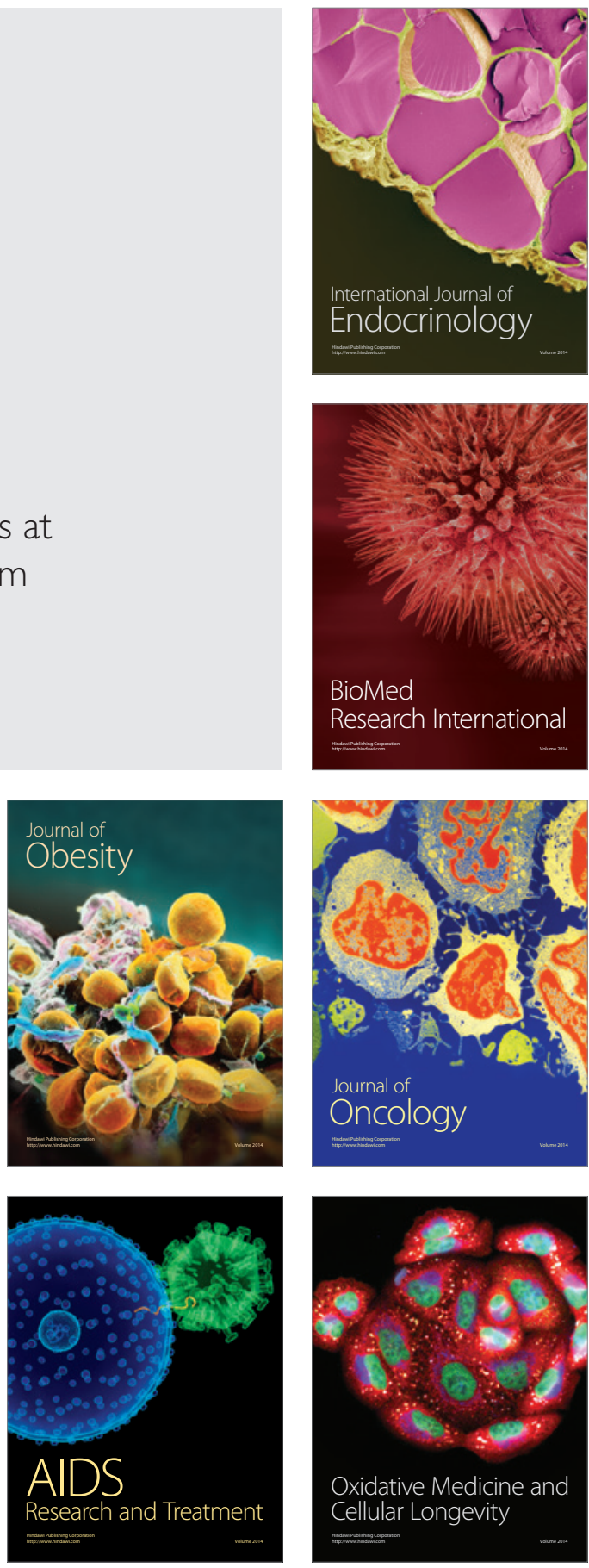